\title{
CONVERGING ONLINE AND CLASS-ROOM METHODS: A PROMISING MODE OF KNOWLEDGE SHARING IN DIGITAL AGE?
}

\author{
Arul George Scaria*
}

\begin{abstract}
The emergence of massive open online courses (MOOCs) is considered as one of the most disruptive changes that happened in the field of education in the last decade. They are playing an important role in democratising access to knowledge across the globe and many countries, including India, are contemplating the use of such courses for addressing their mass educational requirements. In this context, it is important to explore how certain components of MOOCs like online videos and online discussion forums could be converged with traditional classroom methods for giving broader access to education, without compromising the quality of learning and instruction. This article is a case study in this direction in the background of a pedagogical experiment done at the National Law University Delhi, in collaboration with the CopyrightX program of the Harvard Law School. The article describes how a dynamic comparative copyright law course was developed by merging online and offline teaching methods. The article not only analyses the learning implications from this pedagogical experiment for evolving other comparative law courses, but also analyses the broader lessons for designing similar courses in other subjects.
\end{abstract}

\section{INTRODUCTION}

One of the most significant changes that have happened in the field of education in the last decade is the emergence of Massive Open Online Courses ("MOOCs"). Thanks to digital technologies and increasing access to internet, many courses offered by leading institutions across the world are now at least partly accessible to people across the globe.

\footnotetext{
* Assistant Professor, National Law University, Delhi and Affiliate Faculty, CopyrightX. I would like to thank Prof. William Fisher (Harvard Law School) for his comments on the draft version of this article and Ms Rishika Srivastava (National Law University, Delhi) for reading the draft carefully.
} 
While it is hard to find a universally acceptable definition for 'distance education', the concept has been in existence for decades through different channels like correspondence courses, radio, television, and video cassettes. ${ }^{1}$ With some exceptions, most of those channels were limited to dissemination of knowledge within the national boundaries and provided limited opportunities for interactive learning. But the emergence of MOOCs in the year 2008 opened up new learning opportunities sans geographical boundaries. $^{2}$ MOOCs received wider global attention when universities like Stanford and MIT started offering MOOCs. For example, the course titled "Introduction to Artificial Intelligence" offered by Professor Sebastian Thrun and Professor Peter Norvig at Stanford in 2011 was taken by 160,000 students from 190 countries across the globe. ${ }^{3}$ The massive acceptance of such courses also led to the emergence of MOOC platforms like Udacity, Coursera and $\mathrm{EdX}{ }^{4}$

While the importance of MOOCs in democratising access to knowledge is beyond doubt, it is also important to think how we can go beyond MOOCs for providing a dynamic learning experience and broader knowledge sharing. It is particularly important to experiment with how certain components of MOOCs like pre-recorded lecture videos and online discussion forums could be converged with traditional class room methods for more effective learning experiences. This article is a case study based on a recent pedagogical experiment at the National Law University Delhi in collaboration with Harvard Law School. This short introduction is followed by Part 2, which provides an overview of the CopyrightX program offered by Professor William Fisher at Harvard Law School. ${ }^{5}$ Part 3 describes how an affiliate course of the

1 G Sylvia Faibisoff and J Deborah Wills, 'Distance Education: Definition and Overview' (1987) 27 Journal of Education for Library and Information Science 223, 223-230; Edward J Banas and W France Emory, 'History and Issues of Distance Learning' (1998) 22 Public Administration Quarterly 365, 365-381.

2 The course titled 'Connectives and Connective Knowledge/2008' (CCK8) offered in the year 2008 by Stephen Downes and George Siemens of the University of Manitoba, Canada, is considered by many scholars as the first MOOC. Other open online courses were available before the year 2008. But the fact that this course saw enrolment of around 2200 students from across the world has made many scholars consider this as the first MOOC.

${ }^{3}$ C Osvaldo Rodriguez, 'MOOCs and the Al-Stanford Like Courses: Two Successful and Distinct Course Formats for Massive Open Onlince Courses' [2012] European Journal of Open, Distance and E-learning <http://eric.ed.gov/?id=EJ982976> accessed 1 June 2015.

4 Laura Pappano, 'Massive Open Online Courses Are Multiplying at a Rapid Pace' (New York, 2 November 2012) <www.nytimes.com/2012/11/04/education/edlife/massiveopen-online-courses-are-multiplying-at-a-rapid-pace.html> accessed 25 May 2015.

5 'Faculty Profiles' (Harvard Law School) <http://hls.harvard.edu/faculty/ directory/10270/Fisher> accessed 20 May 2015. 
CopyrightX program was designed at the National Law University Delhi to offer students a comparative perspective of Indian and the US copyright law systems. Part 4 of the article analyses the learning implications from this case study for evolving other comparative law courses. Part 5 discusses the broader lessons from this study for designing courses in other subjects for better knowledge dissemination. The article ends with a brief conclusion of the findings.

\section{CopyrightX Program: An Overview}

Professor William Fisher at Harvard Law School is a globally renowned scholar in the field of intellectual property law. From the year 2013, he has been offering a course titled CopyrightX, which focuses on the theoretical and legal foundations of the US Copyright system. ${ }^{6}$ The CopyrightX course is offered between January and May each year. What makes the course unique is the diversity of students enrolled and its unique pedagogical nature. Three are three categories of students for the CopyrightX course. The first group is students enrolled in the residential course at Harvard Law School - a group that Professor Fisher engages with directly. ${ }^{7}$ The second group consists of students who have enrolled for an online version of the course. This group is taught by teaching fellows at Harvard Law School. ${ }^{8}$ While this online course is free of cost, and is open to anyone above the age of 13 who has sufficient command over English, enrolment is limited to approximately 500 students, so as to ensure that teaching fellows can engage with all the enrolled students. ${ }^{9}$ Students of the online course are divided into different sections of 25 students each with this objective. The third group is students from affiliate courses at different institutions located in different parts of the globe. ${ }^{10}$ In the year 2015 , there were 18 such affiliate courses from different parts of the globe. ${ }^{11}$ Unlike the online course, most of the affiliate course sessions are conducted in person, and the students of affiliate courses are taught by one or more teachers of the institution offering the affiliate course.

\footnotetext{
6 'Syllabus' (CopyrightX) <http://copyx.org/> accessed 20 May 2015.

7 'Course Description' (Harvard Law School) <http://copyx.org/harvard-law-school/> accessed 20 May 2015.

8 'Section Details' (<http://copyx.org/sections/> accessed 20 May 2015.

${ }^{9}$ While nearly half of the students who enrolled for this course till date were from within the United States, the remaining students were from more than 90 countries across the world.

10 'Affiliates' (CopyrightX) <http://copyx.org/affiliates/> accessed 20 May 2015

11 ibid.
} 
Students from all the three different categories mentioned above (students at Harvard Law School, students of the online course and students of the affiliate courses) are required to watch pre-recorded lecture videos of approximately 90 minutes every week. ${ }^{12}$ It is important to note here that all these lecture videos are also openly available on YouTube and the videos are not restricted to students who have enrolled for this course. ${ }^{13}$ All the students are also required to read the reading materials provided in their syllabus before attending the classes. Three types of syllabi are used in the program. The syllabus which Professor Fisher uses for his course at Harvard Law School is a fairly elaborate one. ${ }^{14}$ A slightly abridged version of that syllabus is used by students enrolled in the online course. ${ }^{15}$ Faculty teaching the affiliate courses are given considerable autonomy in designing their syllabus. They can use or customise the syllabi designed by Professor Fisher for the Harvard Law School course, or the online course. All the syllabi are made available online and anyone from across the world can use them for their own teaching or research. ${ }^{16}$

The CopyrightX course also provides an online discussion forum exclusively for students who have enrolled in any of the three types of CopyrightX courses. All the students are given unique login IDs for participating in the forum. The students can initiate discussions on any topic in this forum or they can contribute to discussions initiated by other students in the forum. The students are also given an opportunity to take part in special events organised as part of the course at Harvard. ${ }^{17}$ Students can participate in them in person, or through interactive web-casts where they are given an opportunity to pose their questions. The affiliate institutions are also encouraged to organise special events as part of their course. Students who actively participate in class/online discussions and also pass an examination administered at the end of the course are given a certificate from Harvard.

\footnotetext{
12 William W Fisher III, 'Lessons from CopyrightX' in Ruth Okediji (ed), (Cambridge University Press 2015) <http://cyber.law.harvard.edu/people/tfisher/cx/Fisher_ CopyrightX_2015.pdf $>$ accessed 24 November 2015

13 For the list of lectures and links to the videos, <http://copyx.org/lectures/> accessed 21 May 2015.

14 For the syllabus which Professor Fisher used for the Harvard Law School in 2015, see <http://copyx.org/syllabus/hls_syllabus_2015/> accessed 21 May 2015.

15 For the syllabus used in the online course in 2015, see <http://copyx.org/syllabus/ syllabus-for-online-sections-2015/> accessed 21 May 2015.

16 The syllabus used by different affiliate courses can be accessed from the individual webpages of the affiliate courses <http://copyx.org/affiliates/>accessed 21 May 2015.

17 Two special events were organised as part of the 2015 course. They were 'Photography' (with Abelardo Morell and Gerald Frug) on 8 April 2015 and 'Litigating Fair Use' (with Bruce Rich) on 15 April 2015. The recorded videos of these events are available at $<$ http://copyx.org/events/> accessed 30 May 2015.
} 
Students enrolled in the affiliate courses are also given the opportunity to get the certificate, provided they meet the above mentioned requirements. Faculty teaching affiliate courses are given considerable flexibility in designing their exams, with the only requirement being that at least fifty percent of their exam should constitute questions on US copyright law, as the US copyright law is the primary focus of the course.

\section{Comparative Law Version of the CopyrightX Course at the National Law University, Delhi}

National Law University, Delhi was one of the eighteen institutions selected by the Harvard Law School for offering an affiliate course of the CopyrightX program in the year $2015 .{ }^{18}$ I offered the affiliate course as an optional seminar course for the undergraduate students at National Law University Delhi. What made the course unique was its comparative law focus. ${ }^{19}$ Unlike the CopyrightX course at Harvard Law School or the online Copyright $\mathrm{X}$ course, this course aimed to provide students with a comparative perspective of different copyright regimes by focusing equally on both the US copyright law and the Indian copyright law.

As the objective of the course was to give students a comparative perspective, a customised syllabus had to be prepared for the course. The customised syllabus was prepared using the syllabus which Professor Fisher uses for teaching students at the Harvard Law School and relevant materials on Indian copyright law. ${ }^{20}$ The $\mathrm{H} 2 \mathrm{O}$ platform at Harvard was used for preparing and hosting the syllabus. ${ }^{21}$ This platform allows open access to the customised syllabus and anyone interested in the syllabus is free to use the materials provided therein, for any purpose. While there were no technological barriers for the preparation of the syllabus, one major challenge was in finding open access materials on Indian copyright law. As a result, some of the important materials, particularly scholarly articles on the subject which are required for class discussions, could not be shared

\footnotetext{
18 The CopyrightX course was first offered at NLU Delhi in the year 2014 by Ms Chinmayi Arun, Assistant Professor of Law. There were a total of 11 affiliate courses in the year 2014.

19 Some of the other affiliate courses also offered comparative law courses in the context of the copyright laws in their jurisdictions. For the details of the other affiliate courses, See <http://copyx.org/affiliates/> accessed 22 May 2015.

20 The customised syllabus used for the course can be seen at <https://h2o.law.harvard. edu/playlists/12922> accessed 22 May 2015.

$21 \mathrm{H} 2 \mathrm{O}<\mathrm{https}$ //h2o.law.harvard.edu/> is an online platform developed by the Berkman Center for Internet \& Society, with the support of the Harvard Law School Library, for creating, adapting and sharing course materials.
} 
through the online syllabus. Sharing of such copyrighted materials had to be restricted to students enrolled for the course.

20 classes of 2 hours duration each were taught between February and April. All the students who enrolled for the course attended more than $80 \%$ of the classes and more than half of them attended more than $90 \%$ of the classes. The link to the syllabus was provided to the students in advance and in the first meeting they were also given an option to take offline copies of the recorded lecture videos from a USB drive. As mentioned earlier, they also had the option of watching the lecture videos directly on YouTube and interestingly, the survey done by the Copyright $X$ team after the completion of the course indicates that the vast majority of the students used YouTube for watching the lecture videos. ${ }^{22}$ However, why they preferred to watch the pre-recorded videos on YouTube than the offline copies is unclear and this aspect might be further explored in future. ${ }^{23}$

To get more time for in-class discussions and to make full use of the time flexibilities provided by pre-recorded lecture videos, the students were allowed to watch the lecture videos at their convenience. However, for ensuring the quality of class discussions, it was also important to make sure that the students watched the concerned lecture videos before the classes. For ensuring this, all the students were asked to submit their comments or questions on the videos in a shared online document immediately after watching the concerned videos and before the scheduled class. This shared document was open for viewing and editing by anyone enrolled in the course. ${ }^{24}$ This approach provided multiple benefits - First, as a course instructor, I was able to verify that all the students had watched the pre-recorded lecture videos before the class; Second, the limited class time could be better utilised for focused and in-depth discussions; Third, the open nature of the document avoided repetitive questions and comments, as every student could view what other students had already posted in the document; Fourth, it enabled students to do their own research on the issues highlighted in the document before the class, and thereby engage more actively in class discussions; and finally, it also enabled the course instructor to identify and give due attention to areas where students required more attention. All these factors also helped in making classes livelier and more interactive.

Another interesting aspect worth mentioning here is the importance the course gave for collaborative learning experience. The digitally connected

\footnotetext{
22 All except one student mentioned in the post-course survey that they used YouTube for watching the lectures. One student didn't respond to this question.

${ }^{23}$ When the course was offered in 2016, videos were shared only through YouTube.

24 Google Docs was used for this purpose.
} 
world provides many opportunities for peer production of knowledge. ${ }^{25}$ The CopyrightX program has promoted this through multiple channels. At the broader CopyrightX program level, one of the most important steps taken in this regard is the mandate on all the teaching fellows (of the online Copyright course) as well as the affiliate teachers to produce or revise at least one case study as part of the course. ${ }^{26}$ All of these case studies are accessible to all teachers of the program, and this is done with the objective of furthering peerlearning among the teachers of the program. ${ }^{27}$ Some of Professor Fisher's lectures also touched upon different issues relating to peer-production and remixes in the digital age.

As a course instructor, I was also curious to see whether this course also made changes in the behaviour of the students with regard to knowledge sharing. A small experiment was conducted in this regard. As part of the course requirements, all the students of the course were asked to prepare a note on a prominent Indian copyright case. Students were given a list of cases and they were free to choose any case from the list. Students were also required to make a presentation in class on the issues discussed in the case, particularly from a comparative law perspective. When the cases were assigned, it was mentioned that the students may also consider posting an abridged version of their case notes on Wikipedia after the completion of the course. I also clearly clarified that unlike the mandatory nature of submission of case notes, contribution to Wikipedia was a purely voluntary action for the students and the only reason for suggesting it was the fact that Wikipedia pages did not exist for these cases (except one), in spite of their prominent roles in the history of copyright law in India. I also confirmed that none of the students had any previous experience of editing Wikipedia pages. All of them however mentioned that they had used Wikipedia for their academic or other purposes at least once. Interestingly, by the end of the course, nearly all the students had tried to contribute their case notes to Wikipedia. While some of the submissions were later deleted by the Wikipedia reviewers, since they were not in conformity with the Wikipedia article guidelines, many students later reported that this was also a great learning experience for them and that they will continue contributing to such knowledge sharing platforms.

\footnotetext{
25 See generally Yochai Benkler, (Yale University Press 2006); Yochai Benkler, 'Peer Production and Cooperation' in Johannes Bauer and Michael Latzer (eds), (Edward Elgar, forthcoming) < http://www.benkler.org/Peer\%20production\%20and\%20 cooperation\%2009.pdf> accessed 25 November 2015.

26 (n 7).

27 ibid. For example, as part of the affiliate course at NLU Delhi, I prepared a case study on criminal remedies under the Indian copyright law and it could be used by any of the teachers in the CopyrightX program.
} 
Another interesting feature was the manner in which students engaged in extensive peer-discussions on the course contents before and after the class. The shared online document mentioned above played an important role in this regard, as they could see and share some of the important issues discussed as part of the course. Extensive peer-discussions on the course contents were also confirmed in the post-course survey, wherein all the students reported that they had interactions with their peers in person either 'often' or 'extremely often'. ${ }^{28}$ The survey also showed extensive use of instant messaging services for communication among peers regarding the course. $^{29}$ The discussions in the online forum of the CopyrightX program were also reported by some students as helpful in learning the developments in other jurisdictions, though not all students appear to have made full use of the potential for such discussions. Some students reported that the lack of responses to their posts in the forum demotivated them from further postings in the forum. However, it is beyond doubt that the online forum has a very high potential for concrete peer discussions across borders and hence it is considered as an area for further improvements. The in-class presentations by students (on the case notes they prepared) was also an extremely useful tool for peer-learning. The presentations raised interesting discussions within the group and I intentionally limited my interventions in those discussions to the minimum, so as to promote independent thinking and creative arguments among the students. After the presentations, all the notes were also shared among all the students of the course so that all could learn from the notes prepared by their peers.

When the course was offered in 2016, some more components were added for peer-learning. The most important among them was a new writing assignment. As part of the new evaluation scheme, all the students had to prepare a short essay on any contemporary issue in the area of copyright law. In view of the comparative law focus of the course, the only requirement imposed was that the topic should be relevant from a comparative copyright law perspective. Students explored diverse issues like constitutional foundations of copyright law and copyrightability of recipes. The students were asked to upload draft versions of their papers to a shared folder for open peer-review of their works. Students actively participated in the peerreview process and provided many critical comments on each other's work. The open peer-review process not only enabled students to learn about many more contemporary issues in the area of copyright law, but also enabled them to improve their own writing/ research skills with the help of peercomments.

\footnotetext{
${ }^{28} \mathrm{~N}=9$. Extremely often $=6$, Often $=3$.

${ }^{29} \mathrm{~N}=9$. Extremely often $=3$, Often $=6$.
} 


\section{RELEVANCE OF THIS HYBRID EXPERIMENT FOR DEVELOPING MORE COMPARATIVE LAW COURSES}

Comparative analyses play a substantial role in the field of law, though one can see differences among scholars with regard to the extent to which the comparative approach should be used. While transplantation of ideas without due consideration of the local socio-economic and political contexts can be perilous, comparative law offers enormous opportunities to learn from other jurisdictions in law making. ${ }^{30}$ It can be particularly useful in fields like intellectual property law, where many of the theoretical issues are still unsettled and where many of the issues are approached differently in different jurisdictions. Comparative law approaches also assume significance in an increasingly globalising world that advocates for free movement of goods and services beyond borders. Students and practitioners of law who are familiar with the laws of other jurisdictions may get a competitive advantage when they engage with transnational trade disputes. ${ }^{31}$

One of the major bottlenecks for offering comparative law courses in many law schools is the difficulty in finding faculty members who have expertise over the law, culture and contexts in other jurisdictions. Team teaching can be particularly useful for comparative law courses. ${ }^{32}$ As one may notice from the CopyrightX experiment discussed in this article, the hybrid pedagogical approach can address this to a great extent. If online lecture videos, appropriate forums for live interactions and offline teaching methods can be combined in an optimal manner, many more law schools will be able to offer many good comparative law courses. It is also important to note here that such a hybrid approach can provide a more dynamic learning experience for students, as they might not only be interacting with faculty from other jurisdictions, but also students from other jurisdictions with whom they can discuss the topics at more informal levels. For example, the online discussion forum of CopyrightX were used by students enrolled in all the three types of courses offered under the CopyrightX program, and it also meant that it provided immense opportunities for peer-learning. Similar online forums could be jointly created by the host institution of any comparative law course with the support of the faculty members and students from the other jurisdictions.

\footnotetext{
${ }^{30}$ For an interesting discussion on the areas where comparative analyses can be used and misused, see generally, O Kahn-Freund, 'On Uses and Misuses of Comparative Law' (1974) 37 The Modern Law Review 1, 1-27.

${ }^{31}$ Michael P Waxman, 'The Comparative Legal Process throughout the Law School Curriculum: A Modest Proposal for Culture and Competence in a Pluralistic Society' (1991) 74 Marquette Law Review 391, 395-396.

32 ibid 397-398.
} 
However, one must not underestimate the costs and efforts involved in building a good hybrid comparative law program. The most important challenge would be finding faculty members from different jurisdictions who are motivated to offer a comparative law course as a team. Without active offline discussions initiated within the class by the local faculty and adequate online interaction with the expert from the other jurisdiction, the course may not be able to provide a dynamic learning experience. The quality of online videos is also extremely relevant in the success of such a program. Part of the success of the CopyrightX program is the manner in which Professor Fisher's video lectures are structured and used. As law is a constantly evolving subject, it is also important to update the lecture videos regularly. This also involves substantial investment of time and money.

\section{RELEVANCE OF THIS HYBRID EXPERIMENT FOR OTHER SUBJECTS}

Many countries like India are now using or contemplating to use open online courses as a major measure for addressing the educational needs of the country. The prominent ongoing examples from India include different courses offered by the Indian Institute of Science (IISc) and the Indian Institute of Technologies (IIT) through the NPTEL (National Program on Technology Enhanced Learning) platform. ${ }^{33}$ Some of the efforts in the pipeline include SWAYAM (Study Webs of Active-Learning for Young Aspiring Minds), a program conceptualised by the Ministry of Human Resource Development, wherein Professors from different centrally funded institutions are expected to offer open online courses and the e-PG Pathshala project, which intends to create e-contents in 71 subjects for postgraduate level students. ${ }^{34}$

While there are multiple lessons from the present case study for open online courses currently contemplated in different countries as a mode of knowledge dissemination, four of them will be highlighted here. The most important one is the dynamic character of knowledge sharing when interactive offline teaching methods are combined with online teaching tools. The hybrid model provides immense opportunities for peer-learning for both teachers as well as students. This can add substantial value to not just the whole learning process, but also the knowledge creation process.

\footnotetext{
33 For details regarding the different courses offered through the NPTEL platform, $<$ http://nptel.ac.in/> accessed 24 May 2015.

34 For more information on these projects, <http://pib.nic.in/newsite/erelease. aspx?relid=109585> accessed 25 May 2015 and <http://epgp.inflibnet.ac.in/about.php> accessed 25 May 2015.
} 
The second and related issue is the role hybrid models can play in retaining the motivation and engagement of students. One of the biggest challenges faced by many MOOCs is that very few people who sign up for the courses eventually complete the courses. Some studies report the average rate of completion as below $7 \% .{ }^{35}$ As some recent studies have shown, selfdiscipline and organisation can play a vital role in the successful completion of a MOOC. ${ }^{36}$ As our experiment shows, with the hybrid model of combining online and offline teaching methods, one may be able to overcome this issue to a great extent and retain the motivation levels of students for completing the course.

The third issue is the desirability of decentralised teaching approaches through collaborations, particularly in countries like India, which plan to use online courses to address mass educational needs. While the preparation of large number of lecture videos itself is a laudable step on the part of many of the premier institutions, to realise their true potential as knowledge sharing tools for addressing the educational needs of a country, one has to think more on how to use them for enabling dynamic learning experiences for students. For this, it is important to think about building an active network of teachers who may use those courses either in its original form, or in customised versions in different institutions across the country or other parts of the globe. For example, as in the case of the CopyrightX course, many courses could be offered as affiliate courses at different institutions. But to make this effort successful, two factors are important. The first factor is regular interaction between the original course instructor and faculty members who offer the same course or its customised versions. In-person meetings as well as virtual meetings can be particularly helpful in this regard. The second and equally important factor for a shift to the dynamic learning approach suggested, is addressing the issue of increase in workload of the course instructors who offer the course, as they will have to spend considerably more time for interactions and coordination. Due measures should be taken by the host institutions to address the issue of increased workload. This could be through reduction of workload in other courses she is offering or by allowing more teaching assistants for the course.

Finally, it is also important to bear in mind the heterogeneity of the class, while designing online courses for addressing the educational needs, particularly in countries like India. For instance, not all students may have

35 Chris Parr, "Mooc Completion Rates "below 7\%"' (Times Higher Education, 9 May 2013 ) <https://www.timeshighereducation.co.uk/news/mooc-completion-rates-below7/2003710.article> accessed 3 June 2015.

36 Abhijit V Banerjee and Esther Duflo, '(Dis)organization and Success in an Economics MOOC' (2014) 104 American Economic Review 514, 515-518. 
the same level of language competence and this may considerably affect the level of interactions both in the online forums as well as in the class. There may also be many students who are not motivated enough to go through all the readings provided as part of the course to convert the classroom into a space of discussion. There may also be some students who are already passive and some of them may become more passive as the course progresses. For example, as discussed above, some students in my course got demotivated in taking part in online discussion forums as they did not see enough responses to the comments they posted in the online forum of the CopyrightX course. There may also be situations wherein students may get marginalised because of frequent or aggressive or passive or pointless postings. While there are no global solutions to such challenges arising from the heterogeneity of the class, it is important to at least recognise the existence of such challenges while designing and delivering online courses or hybrid courses like the one analysed in this case study.

\section{CONCLUSION}

The year 2012 was described by many as the year of the MOOCs. ${ }^{37}$ But the world has already seen some of the limitations of the MOOCs. ${ }^{38}$ While it is beyond doubt that the MOOCs have played a major role in increasing access to knowledge, it is also important to experiment beyond MOOCs. The pedagogical experiments as part of the CopyrightX course at National Law University, Delhi were a small step in this direction. As is evident from the feedback received from the students who enrolled for the course, the hybrid approach of combining online and offline interactions with the pre-recorded online lecture videos can substantially help in providing a dynamic learning experience. ${ }^{39}$ While such an approach would be particularly helpful in the field of legal education, where comparative analyses have substantial importance, many of the insights from the pedagogical aspects of the course also provide important insights for designing courses in other fields. Only through more such experiments, we may reach the ultimate goal of democratising access to knowledge without compromising the quality of learning and instruction.

\footnotetext{
37 Laura Pappano, 'The Year of the MOOC' (The New York Times, 2 November 2012) http://www.nytimes.com/2012/11/04/education/edlife/massive-open-online-coursesare-multiplying-at-a-rapid-pace.html accessed 15 August 2016.

38 Ben Wolfgang, 'Embrace of Massive Online Courses Rising' (The Washingtion Times, 6 May 2013) <http://www.washingtontimes.com/news/2013/may/6/embrace-of-massiveonline-courses-rising/> accessed 3 June 2015.

39 The survey was conducted by the CopyrightX team at Harvard Law School, towards the end of the course. A web-based survey instrument that protected the identity of the students was used in this regard to gather open and critical responses of the students regarding different dimensions of the course.
} 